\title{
Appraisal of fiber-metal laminate panels reinforced with metal pins deposited by CMT welding
}

\author{
Iaroslav Skhabovskyi a , Natassia Lona Batista ${ }^{\text {b,c }}$, Cesar Augusto Damato ${ }^{\mathrm{d}}$, Ruham Pablo Reis ${ }^{\mathrm{a}, *}$, \\ Edson Cocchieri Botelho ${ }^{\mathrm{b}}$, Américo Scotti ${ }^{\mathrm{a}, \mathrm{e}}$ \\ a Laprosolda - Center for Research and Development of Welding Processes, Faculty of Mechanical Engineering, Universidade Federal de Uberlândia (UFU), Uberlândia, Brazil \\ ${ }^{\mathrm{b}}$ Materials and Technology Department, School of Engineering, Universidade Estadual Paulista (UNESP), Guaratinguetá, Brazil \\ 'Structures and Composite Materials Laboratory, Department of Mechanical Engineering, McGill University, Montreal, Canada \\ ${ }^{\mathrm{d}}$ ALLTEC Materiais Compostos, São José dos Campos, Brazil \\ e Production Technology West, University West, Trollhättan, Sweden
}

\section{A R T I C L E I N F O}

\section{Article history:}

Received 25 April 2017

Accepted 14 July 2017

Available online 15 July 2017

\section{Keywords:}

Fiber-metal laminate panels

Pin anchoring

CMT PIN

Composite-metal hybrid joining

\begin{abstract}
A B S T R A C T
Adhesion between metal and composite is key to fiber-metal laminates (FML). CMT (Cold Metal Transfer) welding has been used for hybrid joints that couple metal pin anchoring with adhesive bonding, but this concept has not been extended to FML panels yet. The objective of this work was to employ metal pins deposited by CMT PIN in FML panels. Panels with different pin deposition patterns were compared with panels without pins in terms of impact energy dissipation and damage characterization, and damage tolerance by means of compression and buckling tests after impact. The pins did not make the FML panels more brittle and the change in deposition pattern did not change the capacity to dissipate impact energy. The pins increased the maximum permanent deformation of the panels after impact, especially if less spaced. The in-plane damage areas were larger in the panels with pins, corroborating the damage depth profile results and their connection with impact energy dissipation. The compression and buckling tests indicated that the pins have potential to improve damage tolerance of FML panels, since a lesscatastrophic behavior was observed. Pin anchoring seems to retard propagation of debonding between metal sheets and composite and hold back delamination within the composite.
\end{abstract}

(c) 2017 Elsevier Ltd. All rights reserved.

\section{Introduction}

The increasing demand for high-performance-lightweight structures has strongly stimulated the development of fibermetal laminates (FMLs). According to Vlot [1], FMLs were developed by the introduction of fibers in the bond lines of laminated metal sheet structures. Cortes and Cantwell [2] describe FMLs as hybrid composite structures based on thin sheets of metal alloys and plies of fiber-reinforced polymeric materials. Vlot [3] states that FMLs combine the advantages of metal materials and fiber reinforced matrix systems. Sinmazçelik et al. [4] justify this combination by considering that metals are isotropic materials, have high bearing strength and impact resistance and are easy to repair, while full composites generally have high strength and stiffness and excellent fatigue characteristics. Botelho et al. [5] state additionally that composite materials provide excellent corrosion resistance. Thus, as mentioned by Salve et al. [6], FMLs take positive

\footnotetext{
* Corresponding author.

E-mail address: ruhamreis@ufu.br (R.P. Reis).
}

characteristics from both metals and fiber-reinforced composites, resulting in superior mechanical properties compared to conventional lamina processed from fiber-reinforced composites or monolithic metals. Despite exhibiting low weights, according to Seydel and Chang [7], composite materials are very susceptive to impact damage. On the other hand, metals are in general heavier, but might have excellent impact resistance. Inside of this context, a very light and impact resistant panel might be obtained by combining the low volumetric mass density of a fiber-reinforced polymer with the high impact resistance of ductile metals, such as aluminum alloys. This possibility had been early highlighted in the development of FMLs. As per Vlot [1], impact damage zones of FMLs are smaller than those found in fiber-reinforced composites alone. Sinmazçelik et al. [4] list the most common FMLs: ARALL (Aramid Reinforced Aluminum Laminate); GLARE (Glass Reinforced Aluminum Laminate); and CARALL (Carbon Reinforced Aluminum Laminate). In summary, FMLs are characterized by a balance of low structural weight and high strength and stiffness, when compared with metals, including aerospace grade aluminum alloys. As a consequence, application of FMLs has been mentioned 
by Rao et al. [8], Salve et al. [6], Li et al. [9] and Sinmazçelik et al. [4] in the aerospace industry.

The adhesion between metal and composite is clearly a key factor to improve the effectiveness of FMLs and several production methods accomplish it by modifying the surface characteristics of the metal side [4]. In this line, but specifically aiming at improving the performance of composite-metal joints, hybrid joining approaches have been developed [10]. They basically rely on macro-scale metal anchorages on the metal surface to interlock the layers of fiber-reinforced polymer and add strength to the adhesive bond. Islam and Tong [11], citing Hart-Smith [12] and Tong et al. [13], explain that hybrid joints use both mechanical fastening and adhesive bonding simultaneously to join similar or dissimilar structural components with increased strength and fatigue performance and less weight and stress concentration. One recent method uses an array of pins deposited on the metal part, before joining, as anchorages (mechanical interlocking) for the composite side. As seen in Graham et al. [14], in this method the pins might be produced by different processes, such as laser metal deposition (LMD) and capacitor discharge stud welding (CDSW). Earl et al. [15] used a proprietary three-dimensional energy beam surface modification manufacturing technique (Surfi-Sculpt) to change the surface of the metal as to have macro pins, without addition of material. CMT (Cold-Metal Transfer) PIN, an arc-welding-based process, is another option also used. It has low cost and flexibility as advantages, for not depending on complex and expensive equipment like LMD and Surfi-Sculpt.

Nowadays, there are other similar joining methods yet almost restricted to composites. Some are used only for textile laminates made with dry-fabric preforms, such as 3D weaving and stitching prior to resin filling. In terms of prepreg composite laminates, zpinning/anchoring is extensively investigated [16-19]. According to Mouritz [19], Z-pins basically work as fine (diameter of 0.2$1.0 \mathrm{~mm}$ ) yet highly stiffness nails (titanium alloy, steel or fibrous carbon composite) that, once penetrated into the prepreg layers before curing, lock the laminate plies together by a combination of friction and adhesion. Z-pinning is used to reinforce fully/locally or for joining composite parts. Still per Mouritz [19], the pin contents typically range from 0.5 to 4.0 vol\% (equivalent to about $8-$ $70 \mathrm{z}$-pins $/ \mathrm{cm}^{2}$ ).

However, Mouritz [19] claims that this technique suits only a few known practical applications, such as in the F/A-8E/ FSuperhornet aircraft to replace titanium fasteners in the air inlet ducts and engine bay doors and in Formula 1 racing cars to reinforce composite roll-over bars. Stelzer et al. [20], nevertheless, used metal z-pins press fitted into predrilled metal sheets as inserts for joining of composites. The main advantage of $z-$ pinning is its effectiveness to increase the delamination resistance, impact damage tolerance and joint strength of prepreg laminates in a simple operation [19], but there are drawbacks. The in-plane tensile, compressive and bending strengths are reduced by the use of z-pins, generally due to factors like breakage of fibres during the z-pinning and even fiber waviness and crimp (microbuckling and kinking). Though, Mouritz [19] believes that, in general, the improvements to the interlaminar properties achieved by $z-$ pinning make up for the reductions to the in-plane mechanical properties.

One can envisage that the use of metal pins deposited by CMT welding might have similar effects on FML panels, since pins deposited with this process could be also treated as a type of $\mathrm{z}$ pin. The CMT PIN is based on its parent process called CMT, in which metal wire is continuously fed and an electric arc (protected by gas) is open between the wire tip and the material to be welded, as in all gas metal arc welding (GMAW) versions. In contrast to conventional GMAW, CMT uses a special torch, which allows reversing the advancing electrode wire. The reversal occurs when the wire touches the weld pool, allowing a smooth transfer of molten material into it (in this instant the current is also reduced drastically, with no short-circuit current peaks) without spattering (loss of material). As the arc is always short, the heat transferred to the work piece is very low, causing just minor metallurgical changes as well as low levels of distortion and discoloration/oxidation (including in the reverse side) in the base metal. The CMT PIN embarks a specific program for realizing pin depositions. After short-circuiting, it causes the wire to stay leaning against the weld pool, with no arc, allowing cooling and consequent welding of the wire to the base metal. Shortly thereafter, a low current is imposed in such a way to heat and soften the welded wire close to its mid length (between the torch and the work piece), but not enough to break it and open the arc, as it is controlled by the CMT PIN software. With the reversing motion started, the consequent soft wire is subjected to a tensile force and is broken (similarly to a tensile test), leaving a pin deposited on the base metal. By changing some of the deposition parameters, it is possible to form pins of different sizes and geometries, as explained in a Fronius [21] literature source.

Ucsnik et al. [22] showed that the use of pins deposited by CMT PIN on the metal side improved the strength of metal-composite joints, when compared to simply bonded ones. Later, Ucsnik et al. [23] and Stelzer et al. [20] confirmed that the pins might be applied to improve the performance of composite-composite joints. They used thin metal sheets with pins on both sides, like inserts, between composite lap joints. According to Graham et al. [14], hybrid joining (adhesive bonding with CMT PIN anchorage) was able to consistently outperform co-cured (adhesive bonding only) specimens in terms of strength and energy absorption at quasi-static and high loading rates, as well as in aspects of damage tolerance after drop-weight testing, environmental durability and mechanical fatigue performance.

As seen, the CMT PIN process seems to have found its main application in enhancing the performance of composite-metal hybrid joints. However, its potential might be also applied to FML panels, as the authors of this work are proposing; arrays of pins on the metal sides would act as an agent of anchorage for the composite sides throughout the panels, contributing to the performance along with the adhesive bonding between the composite and metal sheets. This approach would be somehow different from Z-pinning, which has been employed mainly to improve delamination toughness of composites, but not to reinforce FMLs. Thus, the objective of this work is a first attempt to employ metal pins deposited by CMT PIN on metal surfaces used as layers of FMLs. The methodological approach includes comparing miniaturized FML panels with different pin deposition patterns to a reference (without pins) FML panel and to a panel consisting only of composite, in terms of energy dissipation during drop-weight testing, impact damage extent and compression and buckling tests after impact.

\section{Fabrication of miniaturized panels}

Small-sized FML panels reinforced with metal pins were produced as illustrated in Fig. 1(a). The reference FML panels without pins were produced in the same way, with exception of the pin deposition, whereas the panels consisting only of composite were produced by laying-up of prepregs, followed by pressing and curing. The metals parts were composed of AISI 430 stainless steel sheets $(200 \times 80 \times 0.4 \mathrm{~mm})$. For pin deposition (Fig. 1(b)), a Fronius TransPuls Synergic 5000 power source was used, connected to a VR7000-CMT wire feeder, a PullMig CMT torch and a RCU 5000i remote control unit, with DB0875 data base selected (synergic line CrNi 199 PIN). A 6 axis welding robot was used to move the 

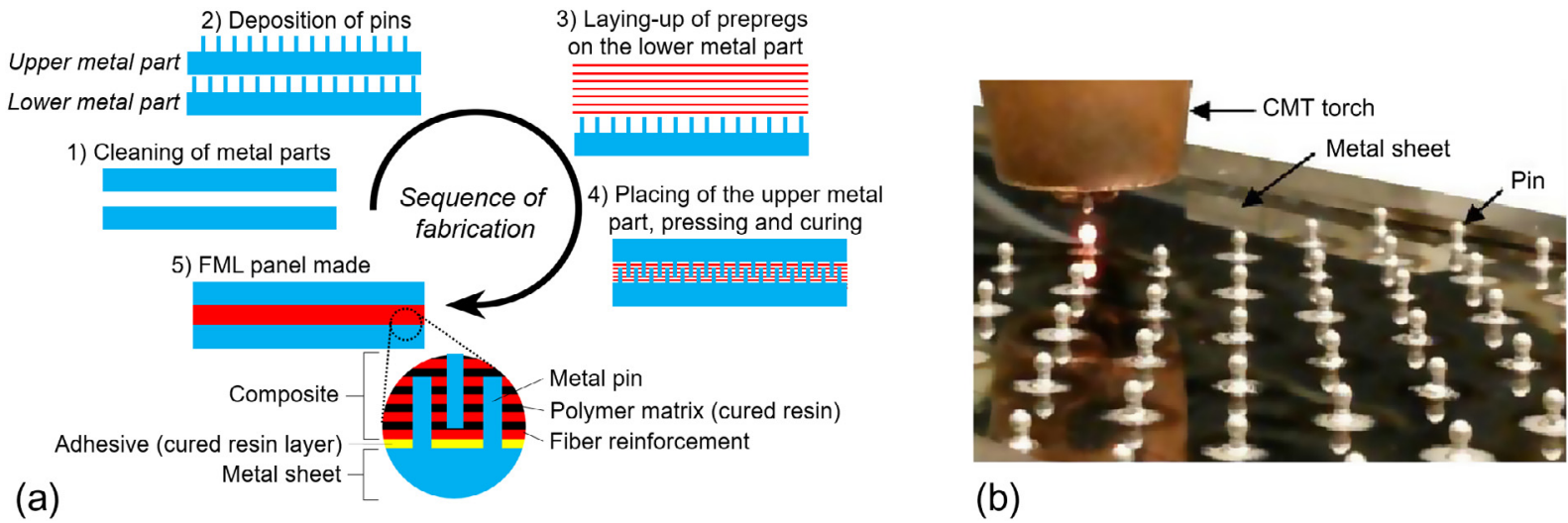

(b)

Fig. 1. (a) Sequence of fabrication of the miniaturized FML panels reinforced with metal pins; (b) Illustration of the pin deposition process.

torch according to the deposition pattern. An AWS ER309LSI filler wire with nominal diameter of $1 \mathrm{~mm}$ (verified value of $0.98 \pm 0.00 \mathrm{~mm}$ ) was used as pin material and Ar with $4 \%$ (verified as $3.7 \%$ ) of $\mathrm{CO}_{2}$ gas at a flow rate of $8 \mathrm{~L} / \mathrm{min}$ was employed to protect the pin deposition. Fronius Contec $\mathrm{MD}^{\circledR}$ contact tips were employed as recommended for CMT PIN. The torch was always maintained perpendicular to the metal parts. The metal surfaces were all previously and homogeneously wiped with acetone wetted cloth. Other input parameters, such as contact-tip to work-piece distance ( $5 \mathrm{~mm}$ ), metal sheet temperature (room temperature $\approx 27^{\circ} \mathrm{C}$ ) and pin deposition sequence were kept unchanged. The CMT PIN process was then parameterised to get minimum-height (considering the thickness of the FMLs) and small ball-head pins (see Fig. 1(b)). Ucsnik et al. [22] has shown that the ball-head shape presents potential in metal-composite hybrid joining. Pins of $2.50 \pm 0.06 \mathrm{~mm}$ in height and $1.40 \pm 0.03 \mathrm{~mm}$ in head diameter were produced, resulting in an average pin weight of $0.023 \pm 0.002 \mathrm{~g}$.

The pin deposition process was monitored by sampling gas flow rate and electrical current and voltage data, as exemplified in Fig. 2. The pin deposition cycle $(\mathrm{T})$ showed repeatability, with a mean period of $5.733 \pm 0.003 \mathrm{~s}$. This cycle consists of the pin deposition time $\left(t_{\text {pin }}=2.595 \pm 0.006 \mathrm{~s}\right)$ and the time to move the torch to the next deposition point, here called transition time $\left(t_{\text {trans }}=3.138 \pm 0.001 \mathrm{~s}\right)$, which was not optimized in this work. The pin deposition time comprises the time for applying shielding gas $\left(t_{\text {gas }}=2.595 \pm 0.006 \mathrm{~s}\right)$, which includes the time for starting the electrical arc $\left(t_{a r c}=0.044 \pm 0.000 \mathrm{~s}\right)$, for welding the wire to the metal sheet ( $t_{\text {weld }}=0.021 \pm 0.000 \mathrm{~s}$ ) and for heating, softening and breaking of the welded wire $\left(t_{\text {rup }}=0.356 \pm 0.008 \mathrm{~s}\right)$.

After pin deposition, all metal parts (with and without pins) went through ultrasonic cleaning by immersion in acetone for eight minutes to remove grease, welding fumes and other unwanted substances, which could impair the adherence of the composite parts. For composite production, prepregs made of glass fiber (8-Harness Satin Weave) and epoxy resin from Hexcel Corporation (product data 7781-38"-F155) were utilized. Each layer of prepreg was cut with dimensions of $210 \times 90 \mathrm{~mm}$, in excess of $5 \mathrm{~mm}$ away from each of the metal sheet edges $(200 \times 80 \mathrm{~mm})$. The prepreg layers were stacked on top of the lower metal parts (with or without pins), always aligning the warp yarns with their length and, consequently, the filling yarns with their width. Next, the upper metal parts were placed aligned to the prepreg layers and lower metal parts. All prepreg handling was executed in a

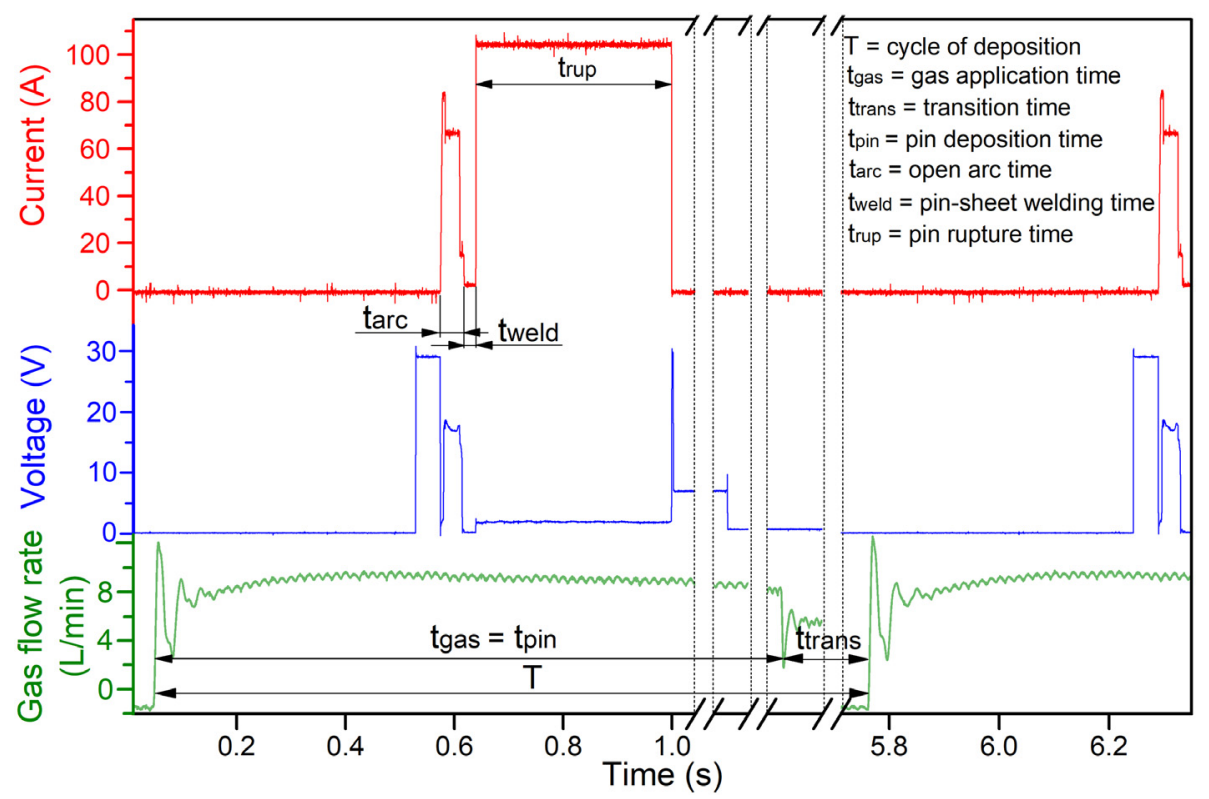

Fig. 2. Pin deposition cycle based on the gas flow rate and electrical current and voltage data. 
white room wearing gloves, avoiding to the maximum the contamination. All miniaturized panels were wrapped with a thin film of polyamide (release agent) and then processed in groups of three in a CARVER ${ }^{\circledR}$ CMG100H-15-C hot-curing press, which curing cycle is showed in Fig. 3. After curing, the excess of composite material at the edges of each panel made was removed with a band saw followed by belt sanding, reaching panels of $200 \times 80 \times 4 \mathrm{~mm}$.

Basic types of miniaturized panels were made (Fig. 4): 1) composite only; 2) conventional FML panel (without pins), i.e., metalcomposite-metal (M-C-M); 3) FML panel with pins, i.e., pined metal-composite-pined metal (MPin-C-MPin). The MPin-C-MPin type was produced using a combination of two levels of pin spans (10 and $20 \mathrm{~mm}$ ) and two deposition patterns (hexagonal and squared). The pins of the upper metal parts were deposited with an adequate displacement in relation to the pins of the lower metal parts, avoiding contact between the upper and lower pins and providing homogenous pin distribution. Each of the resulting six miniaturized panels was replicated once.

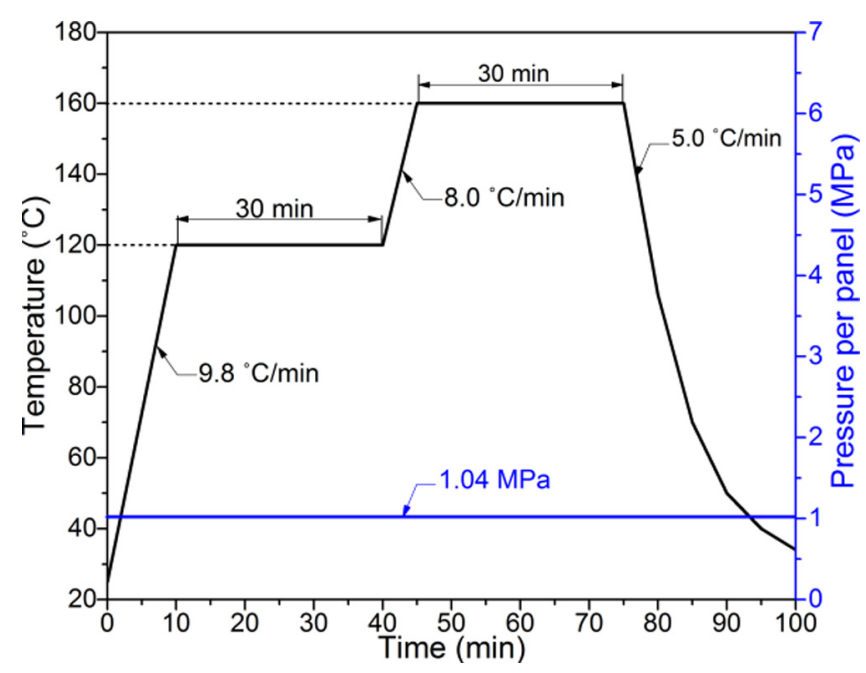

Fig. 3. Curing cycle used for the fabrication of the miniaturized panels.
As shown in Table 1, an attempt to keep the same thickness (approximately $4 \mathrm{~mm}$ ) for all panels was made by having a different number of prepreg layers per type of panel. Pin density was estimated for each pertinent case, by considering the respective number of pins divided by the panel surface area $\left(320 \mathrm{~cm}^{2}\right)$. The FML panels with higher density of pins were slightly thicker because of the consequent larger total volume of pins pushed into the composite parts. However, concerning mass density, usually crucial for FMLs, the presence of pins has only marginal effect, regardless of pin density. The overall average mass density of FML panels with pins was $3.1 \pm 0.1 \mathrm{~g} / \mathrm{cm}^{3}$, the same as in the case of M-C-M (no pins). Thus, the pins, despite in large number, seem to have their potential to add weight counterbalanced by the mass/ volume of composite replaced by their own mass/volume.

\section{Evaluation tests}

\subsection{Drop-Weight testing}

The FML panels reinforced with pins, as conceived in this work, and the reference panels were submitted to impact damage by drop-weight testing. The aim with this test was to verify whether the pins would have positive or deleterious effects on the FML panels and their capacity to absorb impact energy. Based on the ASTM D7136/D7136M-15 standard [24], a rig to impose free fall (from around $1.810 \mathrm{~mm}$ of height) of a constant mass $(2.024 \mathrm{~kg}$ ) over the miniaturized panel surface was devised (Fig. 5(a)). This mass was composed of a $17 \mathrm{~mm}$ spherical head made of hard steel attached to a plain carbon steel cylinder $(50 \mathrm{~mm}$ of diameter and $130 \mathrm{~mm}$ of length). The rig included a latching device for ensuring no mass bouncing (single impact). A commercial high-speed camera filming at 2000 frames per second with $90 \mathrm{~mm}$ f/2.5 macro lens and frontal lighting was employed to quantify the energy (based on mass speed) involved in the impacts. The free fall height aimed a potential energy according to the thickness of each panel and a level sufficient for causing apparent damage at impact, which resulted in $8.5 \mathrm{~J}$ per each millimeter of panel thickness (gravitational acceleration considered as $9.81 \mathrm{~m} / \mathrm{s}^{2}$ ). Fig. 5(b) shows the upper and lower surfaces of all types of panels after impact.

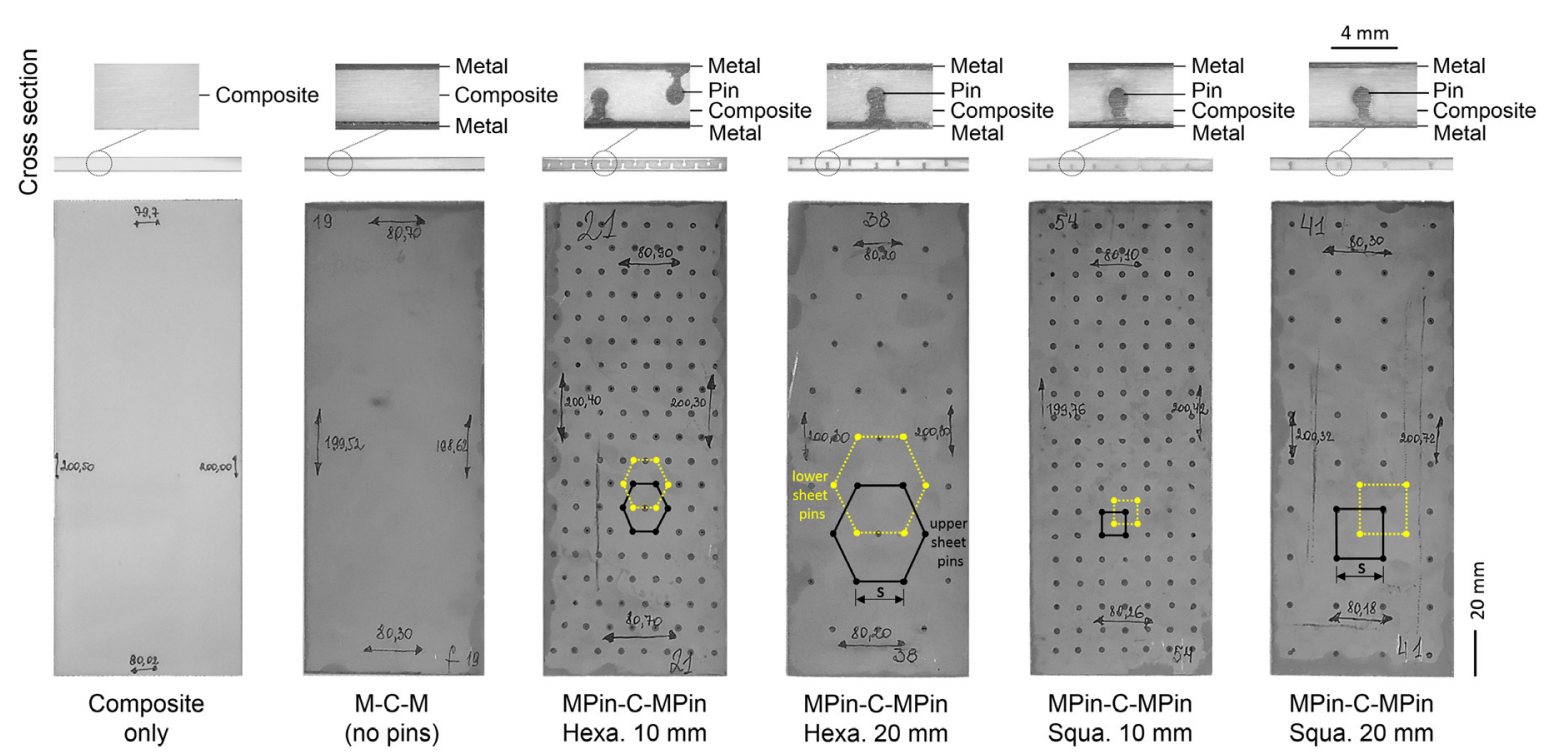

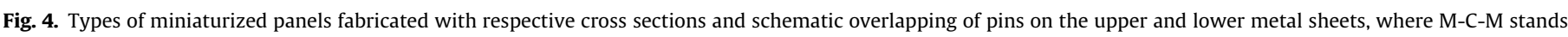

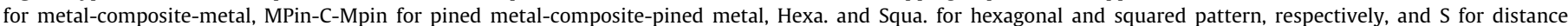

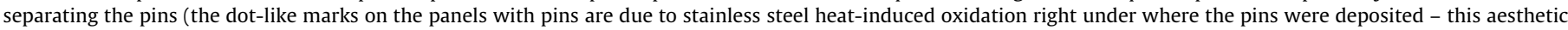
effect could be avoided with inert gas back purging). 
Table 1

Characteristics of the miniaturized panels.

\begin{tabular}{|c|c|c|c|c|c|}
\hline Panel type & Pins per panel & Prepreg layers per panel & Actual thickness (mm) & Pin density $\left(\mathrm{pin} / \mathrm{cm}^{2}\right)$ & Mass density $\left(\mathrm{g} / \mathrm{cm}^{3}\right)$ \\
\hline Composite only & 0 & 22 & $4.24 \pm 0.00$ & 0 & 2.1 \\
\hline M-C-M (no pins) & 0 & 19 & $4.34 \pm 0.00$ & 0 & 3.1 \\
\hline MPin-C-MPin Hexagonal $10 \mathrm{~mm}$ & 285 & 16 & $4.29 \pm 0.00$ & 0.89 & 3.1 \\
\hline MPin-C-MPin Hexagonal 20 mm & 63 & 16 & $3.93 \pm 0.01$ & 0.20 & 3.2 \\
\hline MPin-C-MPin Squared $10 \mathrm{~mm}$ & 293 & 16 & $4.49 \pm 0.00$ & 0.92 & 3.0 \\
\hline MPin-C-MPin Squared $20 \mathrm{~mm}$ & 67 & 16 & $3.98 \pm 0.01$ & 0.21 & 3.2 \\
\hline
\end{tabular}

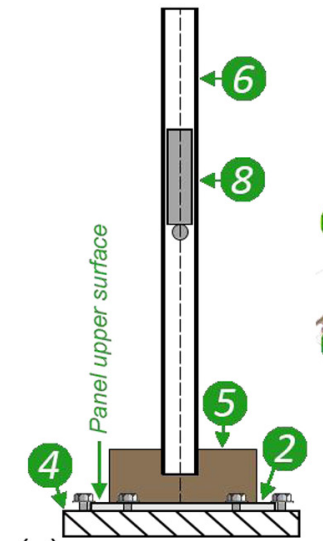

(a)

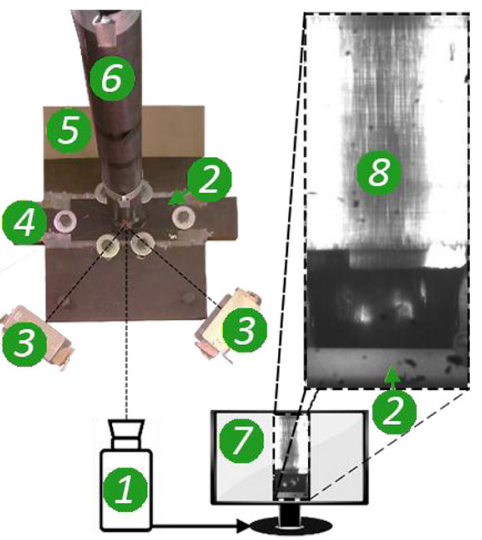

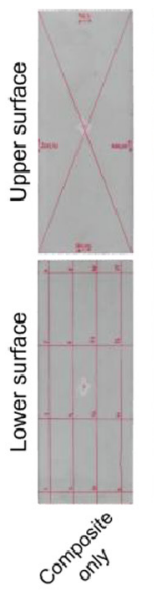

(b)
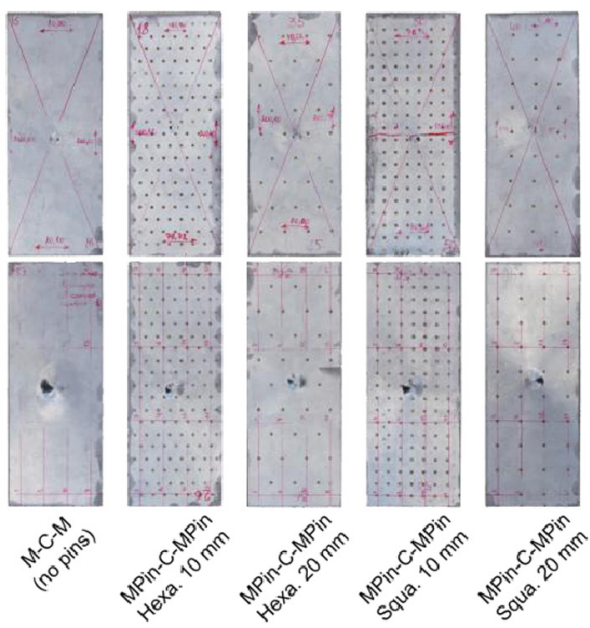

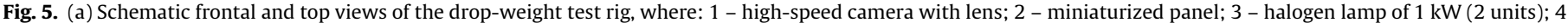

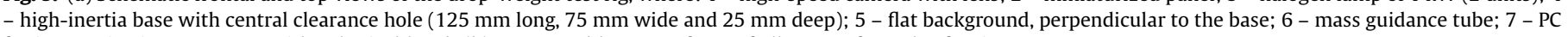
for image viewing; 8 - mass with spherical head; (b) Upper and lower surfaces of all types of panels after impact.

High-speed images were used for determination of the falling/ raising mass velocities immediately before/after impact, based on displacements (visualized from frame to frame) of its spherical head lower surface and respective time lapses, as seen in Fig. 6 (a). A fitting curve, taking into account the non-uniform rectilinear motion due to gravity of the falling/raising mass, was figured out for each panel (including replications) and the velocities at the panel upper surface level were estimated by extrapolation. The velocity right at the end of the fall (actual impact) is referred as impact velocity and the velocity right at the beginning of the rebound as return velocity, which resultant average levels varied respectively from 5.69 to $6.11 \mathrm{~m} / \mathrm{s}$ and from 2.69 to $4.30 \mathrm{~m} / \mathrm{s}$, as indicated in Fig. 6(b). According to Ursenbach et al. [25], the drop-weight test applied was classified as of low impact velocity (between 1 and $10 \mathrm{~m} / \mathrm{s}$ ). Farooq and Myler [26] consider an impact as of low velocity when an object impacts a target without penetrating it, situation observed for all panels tested in this present work.

The velocities involved in the impacts, in turn, were used to calculate the impact and return energies. Impact energy was considered as the kinetic energy of the falling mass just before actual impact (fall height tending to zero - panel upper surface level before impact). Analogously, return energy was taken as the kinetic energy of the raising mass at the beginning of the rebound after the impact (rebound height tending to zero - panel upper surface level before impact). Energy dissipation during impact was assumed as the relative drop in the kinetic energy due to impact. The impact energy quantities were represented by three ways: energy, specific energy (considering the panel mass density) and energy per unit of panel thickness, as presented in Fig. 7. As seen in Fig. 7(a), the impact energy was always around $35 \mathrm{~J}$, being the small fluctuation due to minor differences in the thickness of the panels (Table 1), which required slightly different potential energies (fall heights) as stated before. The return energies and energy dissipations were also similar for all FML panels, although, for these two quantities, the panel consisted only of composite presented significant differences; the FML panels dissipated around $80 \%$ of the kinetic energy, whereas only $44 \%$ was dissipated by the panel consisting only of composite.

Considering that energy dissipation during impact can be taken as a sensitive measure to assess panel performance, the above results indicate that the composite by itself has more intense elastic behavior, while the FML panels absorb more energy during impact, due to the metal plastic deformation. However, if the mass density of each case (see Table 1 ) is taken into account, as shown in Fig. 7(b), all panels, including the panel consisting only of composite, dissipated similar levels of specific energy during impact, around $25 \%$. Thus, the fact of adding weight, in consequence of the use of pins as anchorages, does not penalize the capacity of dissipating impact energy. On the other hand, if the thickness of each case (see Table 1) is taken into account, as presented in Fig. 7(c), the panel consisting only of composite should be almost twice as thick to exhibit the same impact energy dissipation capacity of the FML panels, including those with pins. In general, the presence of pins as anchorages inside the FML panels did not seem to have any significant effect concerning the capacity of the panels to absorb impact energy. Therefore, the pins, at least for the impact conditions applied, did not make the FML panels more brittle. In addition, the change in the deposition pattern of the pins, at least for the remaining conditions, did not show any effect concerning the capacity of the panels to dissipate impact energy.

\subsection{Impact damage characterization}

Due to the intrinsic difficulties related to panel damage assessment, the damage extent after drop-weight testing was estimated 

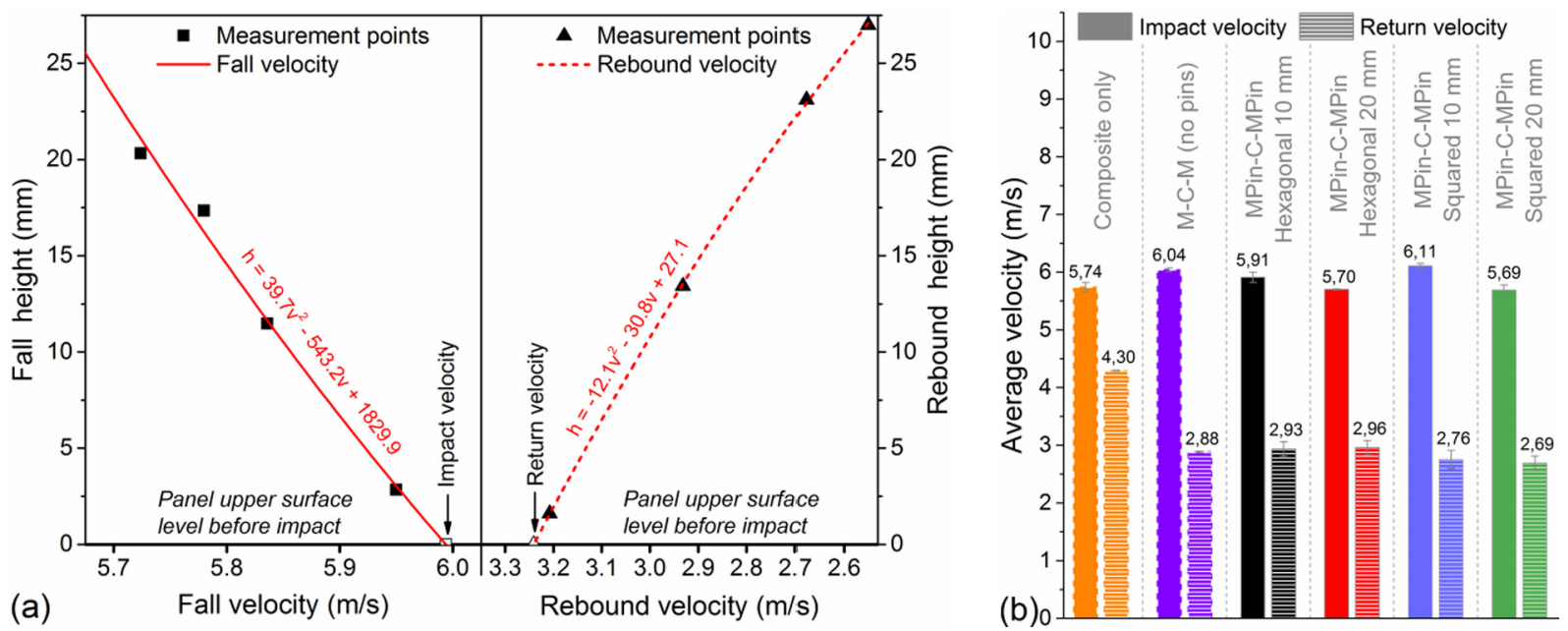

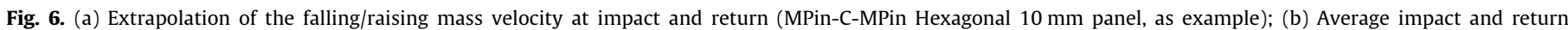
velocities for each panel ( $h=$ height; $v=$ velocity).
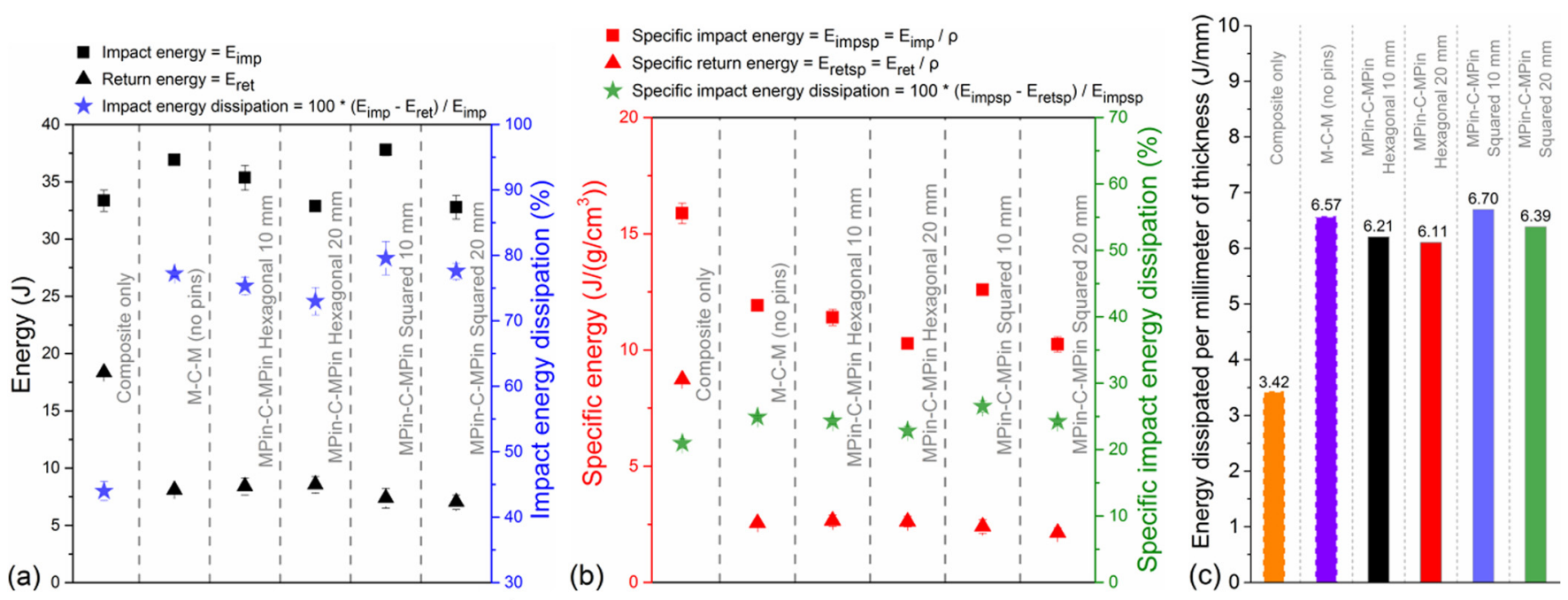

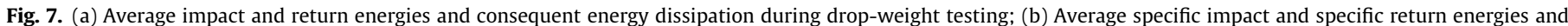

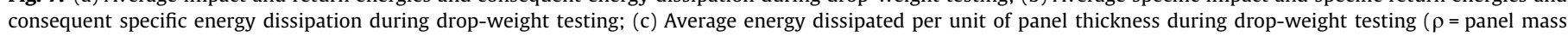
density).

by two nondestructive testing methods; 3D digital probing, to delineate damage depth profile, and infrared thermography, to estimate the damage area.

\subsubsection{Damage depth profile}

The through-thickness damage extent, i.e., the depth profile of the impact damage (permanent deformation), was found by measuring the vertical displacement of the central transversal and central longitudinal lines drawn in all panels before drop-weight testing. The edges of the panels, both in length and width, were taken as references without permanent deformation after impact. A commercial manual-floating-type coordinate measuring machine, with $1 \mu \mathrm{m}$ of resolution, was used for taken the measurements. The damage profile was determined by scanning the upper and lower surfaces of the panels, as exemplified in Fig. 8. As seen, the measuring mesh was reduced to $5 \mathrm{~mm}$ near the damage area, against $10 \mathrm{~mm}$ in the rest of the surface of the panels.

The average damage depth profiles of each panel are shown in Fig. 9(a). As the profiles were nearly longitudinally and transversally symmetrical, only half of the panels' length and width is represented. In general, the damage profiles found in each surface of the FML panels with pins were similar, longitudinally as well as transversally, to the profiles found in the conventional FML panel

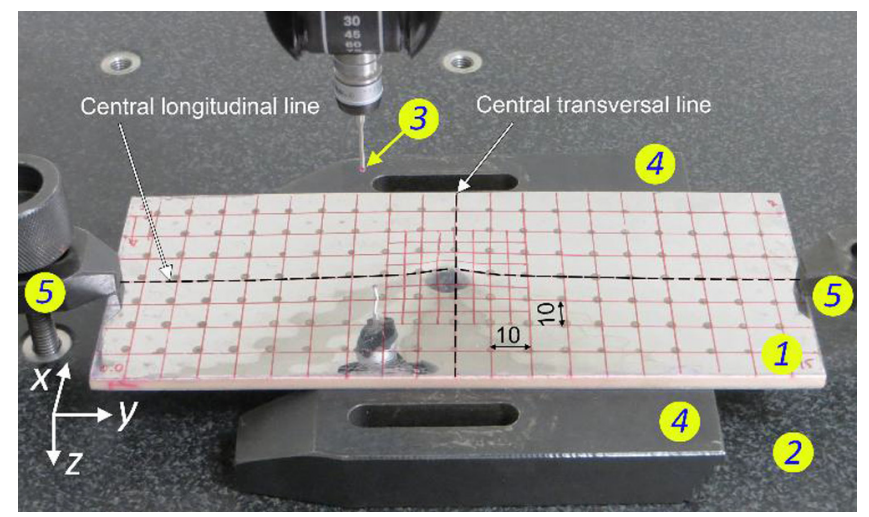

Fig. 8. General setup for damage depth profile determination (lower panel surface as example), where: 1 - damaged miniaturized panel; 2 - work table; 3 - 3D digital probe (touching head); 4 - support; 5 - clamping. 

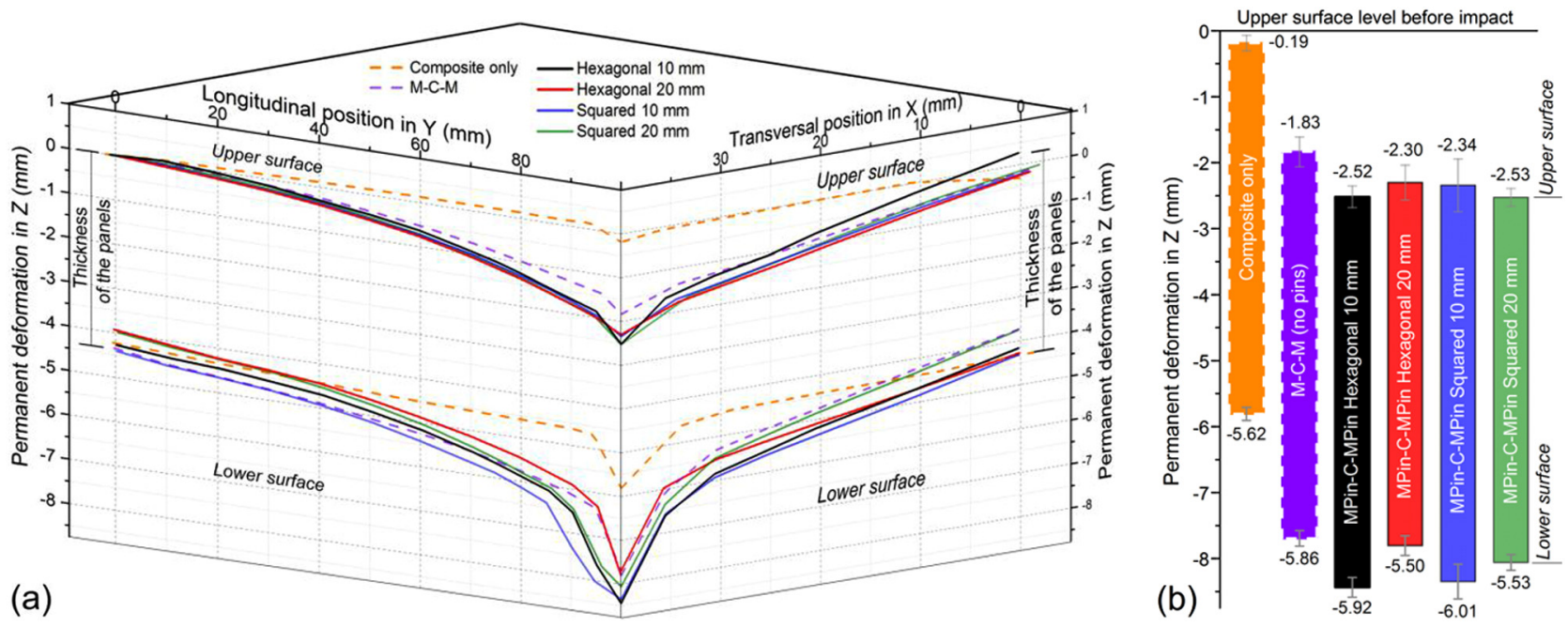

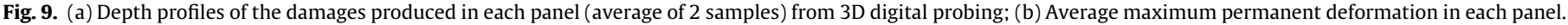

(M-C-M (no pins)). However, the presence of pins tends to increase the permanent deformation of the panels after impact as complementally shown in Fig. 9(b). The case consisting only of composite clearly exhibited less permanent deformation, but in a concentrated profile, which is typical of composites, because they delaminate extensively in the lower layers when impacted.

Two reasons might be pointed out to explain these results: the number of prepreg layers used, that is, the share of composite in each case, and the presence of pins as anchorages. It is also noted that the upper and lower surfaces exhibited different typical deformation profiles. In all panel types, the depth profile was more concentrated (shorter and shallower) in the upper surface than in the lower surface. The falling mass head might have tended to replicate its spherical contour on the upper surface, with the extent limited by the panel own thickness, which would work as restriction against deformation. The final damage extent at the lower surface, in contrast, is limited by the edges of the central clearance hole of the base of the drop-weight test rig, which are reasonably far away. It is even possible to observe that the change in damage depth profile is more gradual along the central longitudinal line (edges of support $125 \mathrm{~mm}$ apart) and more abrupt along the central transversal line (edges of support $75 \mathrm{~mm}$ apart). The panels consisted only of composite, formed by 22 layers of prepregs, behaved more elastically and dissipated less energy during impact, as shown in Fig. 7. As the conventional FML (M-C-M (no pins)) and FML panels with pins had respectively 19 (13.6\% less) and 16 (27.3\% less) layers of prepregs, they behaved less elastically, exhibiting more permanent (plastic) deformation and consequently dissipating more energy during impact (Fig. 7).

Regarding the role of the pins as anchorages, focus of this investigation, they seem to combine with adhesive bonding to keep the composite attached to the metal sheets more effectively during impact - the pins transfer to the composite the metal permanent (plastic) deformation and respective capacity to dissipate impact energy. This effect was slightly more pronounced with a shorter pin span (10 versus $20 \mathrm{~mm}$ ), which seems to make sense, since a higher density of pins (shorter separation distance) would increase the number of anchorages acting inside and around the damage area. In the conventional FML panel (M-C-M (no pins)), adhesionrelated joining mechanisms operate alone. A correspondent tendency was observed in the impact energy results (Fig. 7). This effect will be further investigated in the future considering shorter pin spans, such as $5 \mathrm{~mm}$. Corroborating the impact energy results (Fig. 7), the change in the deposition pattern of the pins, at least for the remaining conditions, did not have any effect on the damage depth profiles.

\subsubsection{Damage area}

The in-plane damage extent, hereinafter called damage area, of the panels after impact was estimated by infrared thermography using an active pulsed transient transmission technique. All panels were also inspected before impact for as-manufactured integrity check. Several investigations have shown the effectiveness of infrared thermography for inspection of composite structures, including

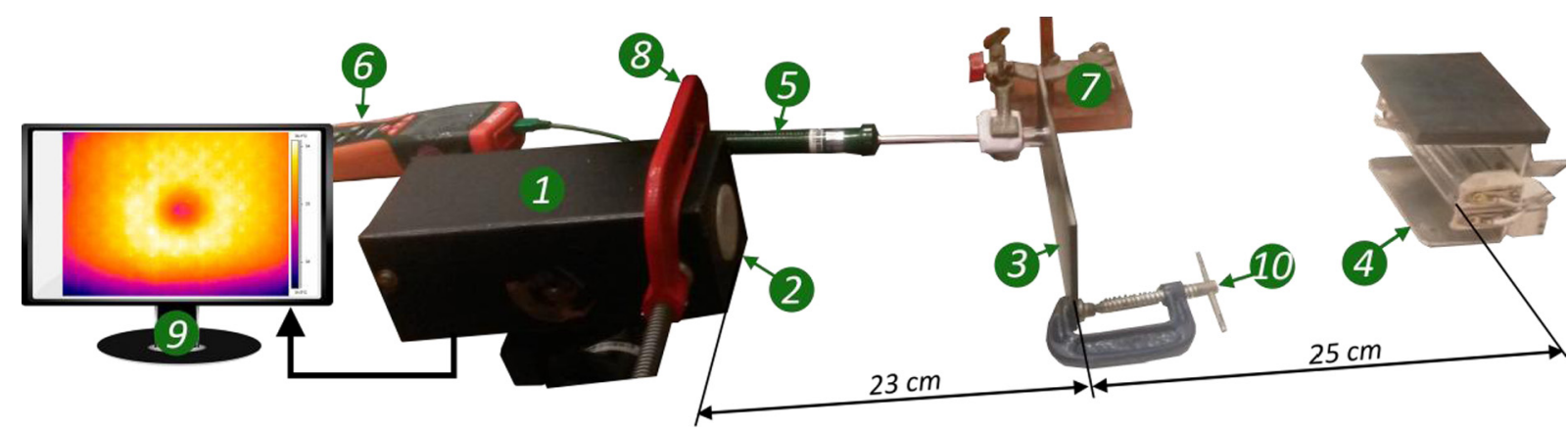

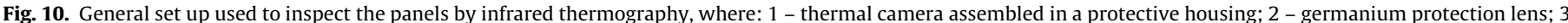

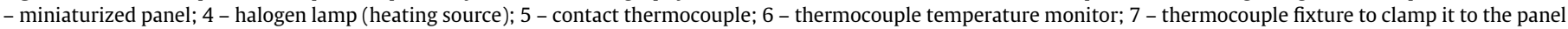
surface; 8 - thermocouple handle bar fixture; 9 - PC with thermogram analysis software; 10 - panel holder. 
for delamination-like flaws resultant from impact [27-31]. Fig. 10 shows the general set up used to inspect the panels and estimate the extent of the damages. A commercial thermal camera with germanium protection lens, accuracy of $\pm 2 \%$ of reading, image resolution of $320 \times 240$ pixels and acquisition rate at $60 \mathrm{~Hz}$, was used. Before being examined by infrared thermography, all panels were spray-painted in matte black to avoid reflectance issues caused by the metal sheets (the AISI 430 sheets are highly reflective). For inspection, the camera was placed perpendicular to and at a distance of $23 \mathrm{~cm}$ from the panel upper surface. The center of the panels (region of impact) was always aligned with the camera lens. The heating was provided by a halogen lamp consisting of two incandescent bulbs (with $1 \mathrm{~kW}$ of power each) placed on the opposite side of the thermal camera and at a distance of $25 \mathrm{~cm}$ from the panel lower surface. The temperature reached in the panel upper surface was used as criterion for heating stop. This reference temperature was $75^{\circ} \mathrm{C}$ and it was verified through a K-type contact thermocouple. For analyses of the thermograms, the camerarelated Thermocam Research $2.9^{\circledR}$ software was employed. Typically, the indications of damage in this case, usually associated with delamination in composite layers and/or debonding between the composite and metal sheets, appear as regions of cold contrast in the thermograms. As delamination and/or debonding correspond to a breakage in the material continuity (physical separation), it significantly reduces the local thermal conductivity and hence the temperatures. These flaws act as thermal resistance to the heat diffusion in series with the global resistance of the sample, in this case the panel, as a thin air layer [27].

The thermographic damage extent measuring procedure adopted is not standardized and was exploratorily applied here. The capturing of thermograms started at the same time as the heating application for all panels (halogen lamp switched on). The time to reach the reference temperature (here assumed as $75^{\circ} \mathrm{C}$ ) and to stop heating (halogen lamp switched off) was around $180 \mathrm{~s}$. As basis for analysis, all data were sampled at 9 fixed time instants from the heating start. The correspondent time-related images were used for qualitative evaluation while the associated temperature profiles were used for quantitative estimation of the extent of the in-plane damages. The temperature profiles were taken in two orthogonal lines crossing the damage area central indication in the thermal images. Based on these temperature profiles, the damage area in each case was estimated by Eq. (1) for all sampling times. The length across each orthogonal line with temperature fall (indication of damage) was measured through an image analysis software. Fig. 11 shows examples of damage analysis by comparing thermal images and temperature profiles of pan- els before and after impact at the same instant of time. As seen, there is no indication of temperature fall in the central region of the panels before impact and, as consequence, the temperature profile, as exemplified in Fig. 11(c), is nearly unchanged along the central horizontal and central vertical lines. The same was observed for all panels inspected before impact, which indicates general integrity (adhesion of all layers of composite and metal and inexistence of dry spots) in the as-manufactured condition. As expected, the panels consisting only of composite conduced less heat and appeared not as hot as the panels with metal parts (sheets and pins); in contrast to metals, polymer matrixes are generally known for their low thermal conductivity. In the images after impact, on the other hand, there is evident contrast of temperatures with a cold area centralized in the panels. This cold area is an indication of damage and its extent, as shown in Fig. 11(c), is based on the drop of correspondent temperature profiles. Corroborating the results from the analyses of damage depth profile in each case, and their connection with the impact energy dissipation during drop-weight testing, the thermal images reveal indications of damage visually larger for the FML panel with pins, intermediate for the conventional FML panel (without pins) and smaller for the composite panel.

$D_{\text {area }}=\pi \times \frac{L_{H}}{2} \times \frac{L_{V}}{2}$

where:

$D_{\text {area }}$ is the estimated damage area $\left(\mathrm{mm}^{2}\right)$;

$L_{H}$ is the damage horizontal extent $(\mathrm{mm})$;

$L_{V}$ is the damage vertical extent $(\mathrm{mm})$.

Fig. 12(a) shows the average estimated damage areas at different sampling times after heating start. As expected, the indications of damage area first grow and then diminish as the heating time increases. First, as the heat flow and temperatures build up, the temperature profiles and equivalent damage indications become apparent and reach maximum extensions. After that, the continuous heat flow increases the temperatures in the regions of damage and the indications (temperature contrasts) tend to be reduced as the panels are heat-saturated. Therefore, the damage areas were taken as the average maximum indications verified in each case. Fig. 12(b) presents elliptic representations (based on Eq. (1)) of these maximum damages, where the long axis is aligned with the longitudinal direction of the panels, once they were mounted on top of the central clearance hole in the base of the dropweight test rig (Fig. 5). (a)

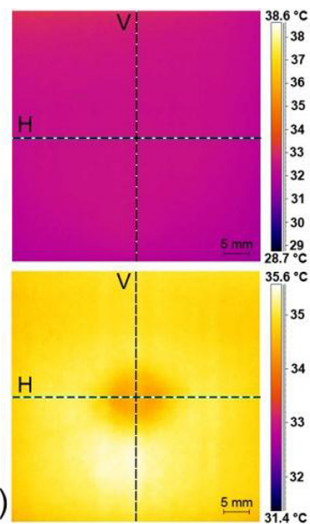

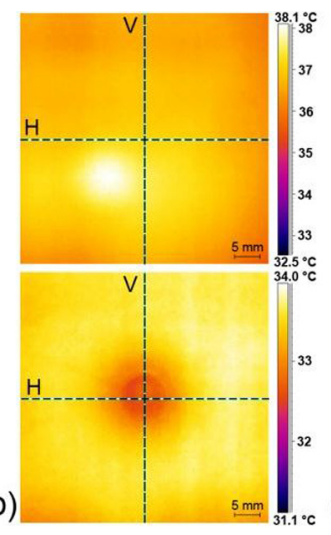

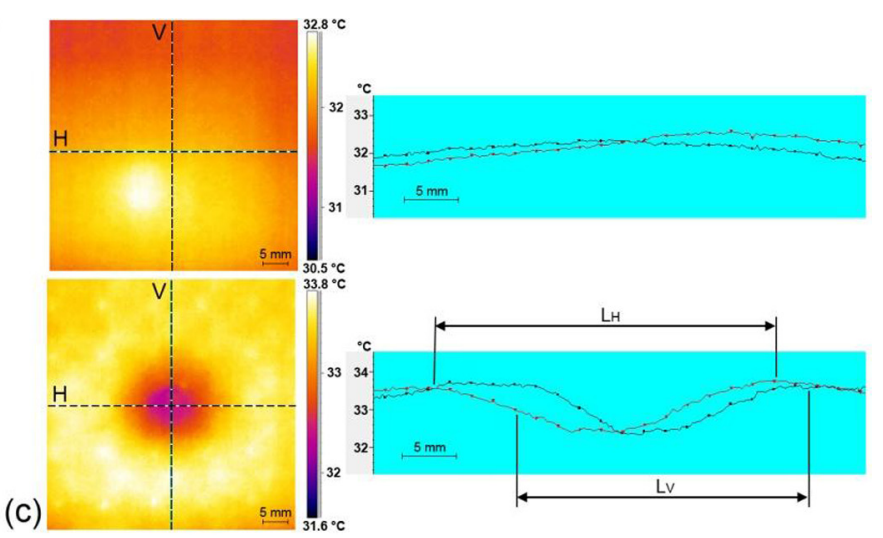

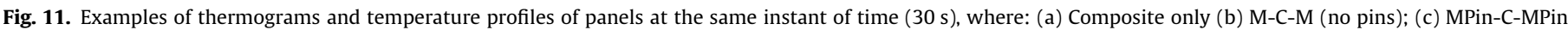

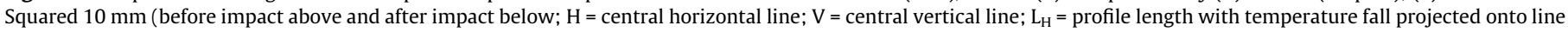
$\mathrm{H}$ (damage horizontal extent); $\mathrm{L}_{V}=$ profile length with temperature fall projected onto line $\mathrm{V}$ (damage vertical extent)). 


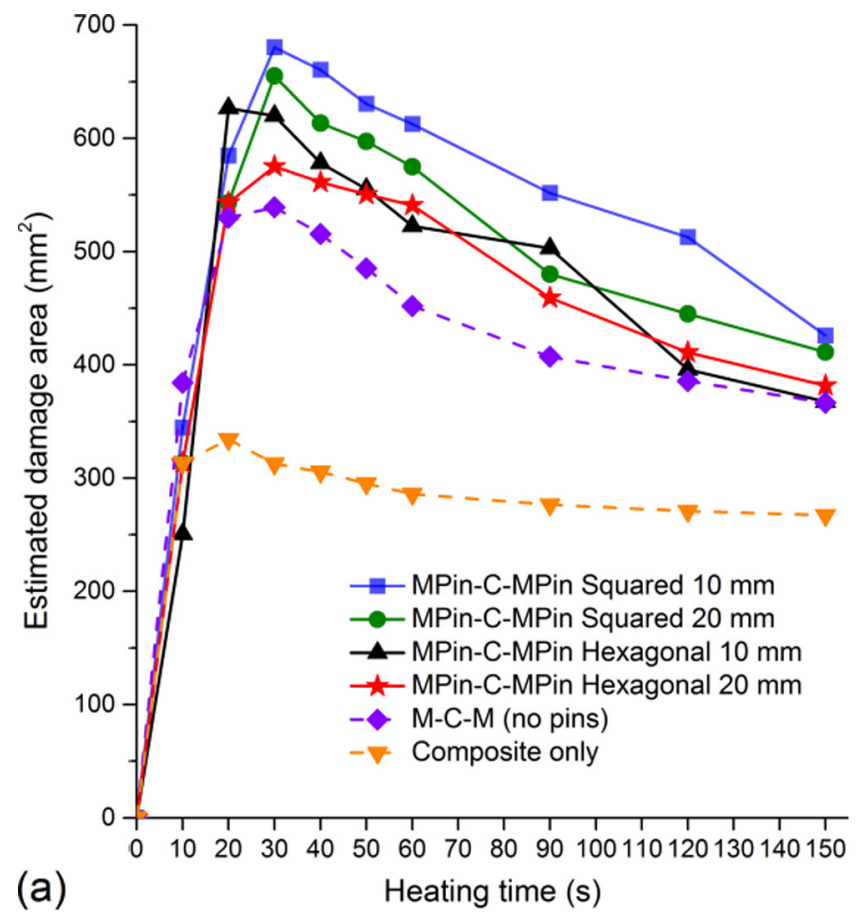

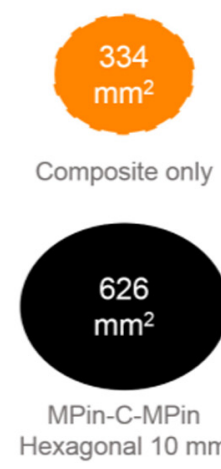

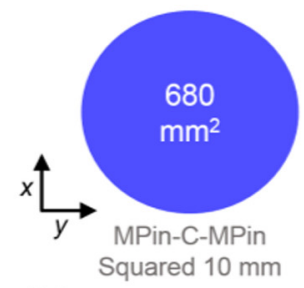

(b)

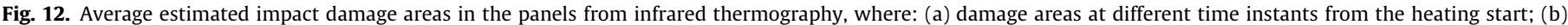
Proportional representation of maximum damage areas.

As seen, the FML panels with pins as anchorages, especially the case codified as MPin-C-MPin Squared $10 \mathrm{~mm}$, had larger damage areas, which seems to be linked to its capacity to dissipate impact energy and transform it into permanent deformation (larger plasticity). Concerning the damage extent, the pattern of pins seems to play a role, as the hexagonal deposition pattern, regardless of the distance separating the pins, reduced the damage area. The panel consisted only of composite had by far the smallest damage, consistent with its low capacity to dissipate impact energy and small permanent deformation (large elasticity). The conventional FML panel (M-C-M (no pins)) exhibited intermediate behavior as in the impact energy dissipation and damage depth profile analyses. Besides the permanent deformation, as discussed before, propagation of damage with the pins and debonding of the metal sheets from the composite seem to be other mechanisms for impact energy dissipation. Even though there was repeatability in the damage area results, respectively with 10.57 and $5.02 \mathrm{~mm}^{2}$ as maximum and minimum standard deviations, and a reasonable logical connection with the results of impact energy dissipation and damage depth profile, imprecision related with thermal radiation emitted in the ambient and thermal camera angle, for example, might bring uncertainties to the infrared thermography method. Further evaluations, including panels with shorter spacing among pins, should be considered.

\subsection{Compression and buckling tests after impact - Damage tolerance}

According to Ishikawa et al. [32] and De Freitas and Reis [33], the resistance of composite panels to in-plane compressive stresses is strongly impaired by the presence of delamination-type damages, culminating in expressive reductions in buckling resistance of components. In that way, all types of panels were subjected to compression and buckling tests after impact (dropweight test) as initial investigation on the influence of pins on damage tolerance. For each type of miniaturized panels fabricated, one was tested for compression and another for buckling. An elec- tromechanical universal testing machine was used. Upper and lower supports for the panels were designed and built to allow proper alignment and fixture for both tests, as shown in Fig. 13 (a) and (b). In accordance with ASTM D7137/D7137M-12 standard [34], the testing speed (upper head moving rate) was always set at $1.25 \mathrm{~mm} / \mathrm{min}$.

\subsubsection{Compression after impact}

Fig. 14(a) shows the evolution of compressive load versus axial displacement in compression tests of all panel types after impact damaging. The use of metal sheets along with the composite increases the compressive modulus of the panels, but this effect is not so clear with addition of pins. The resultant values of maximum compressive load and correspondent axial displacements are shown in Fig. 14(b). As seen, the panel consisting only of composite supported one of the lowest maximum compressive loads, an indication of its typical low damage tolerance. The conventional FML panel (M-C-M (no pins)) tolerated similar maximum compressive load, despite its slightly lower correspondent axial displacement. Concerning the panels with pins, all types exhibited less catastrophic behavior - there seems to be a residual strength that leads to higher loads at longer axial displacements. In addition, the MPin-C-MPin Squared $20 \mathrm{~mm}$ panel and especially the MPin-CMPin Hexagonal $10 \mathrm{~mm}$ panel achieved maximum compressive load values significantly higher than the rest of the panels, which took place at axial displacements slightly longer. The reasons behind this result will be investigated in future complement tests. This less catastrophic behavior of the pinned miniaturized panels deserves further confirmation, using more appropriate tests to assess delamination toughness, such as Iosipescu Shear test.

\subsubsection{Buckling after impact}

First, in order to have a general view on how the impact from the drop-weight tests would influence the performance of panels with pins, two extra MPin-C-MPin Squared $20 \mathrm{~mm}$ panels, one with and one without impact damage, were subjected to the buck- 

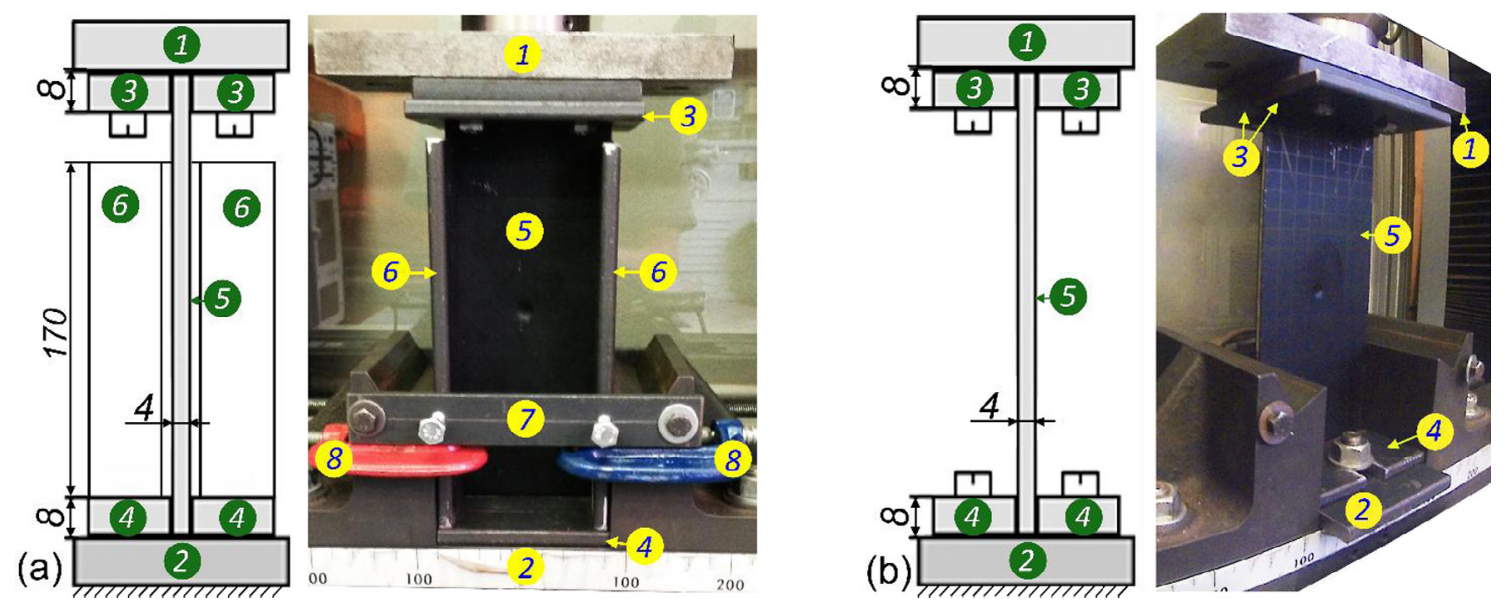

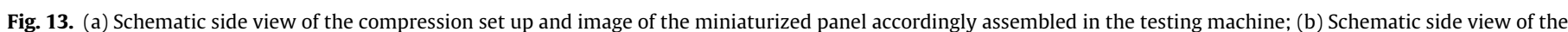

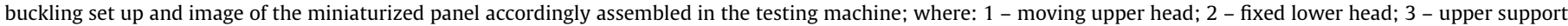
(two parts); 4 - lower support (two parts); 5 - panel; 6 - support fixture side plates; 7 - auxiliary holding bar; 8 - auxiliary clamps (dimensions in mm).
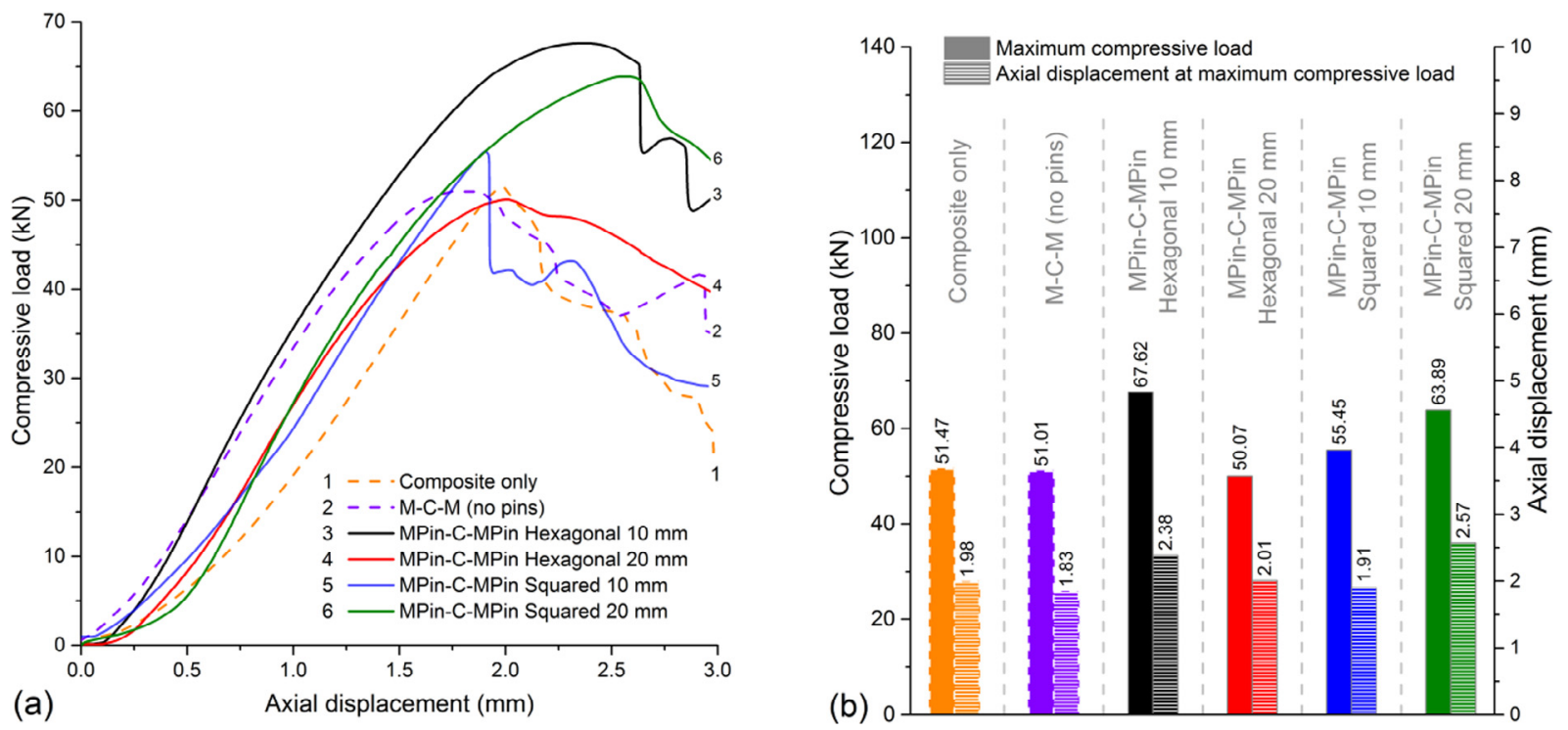

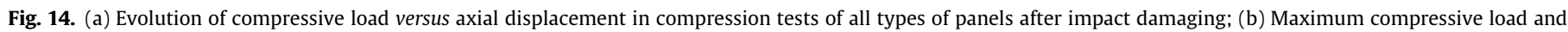
correspondent axial displacements from compression tests of all types of panels after impact damaging.

ling test. Fig. 15(a) shows the resultant evolution of load versus axial displacement and testing time in each case. As seen, the behaviors are initially, during the in-plane compression phase (1), very similar with no apparent difference in compressive modulus, but the damaged panel had a maximum compressive load $1 \mathrm{kN}$ lower and a correspondent axial displacement and testing time slightly shorter. This indicates the damage did not change the panel as a whole, but its localized influence is perceived once sufficient load is applied. After bearing maximum loads, the panels with and without damage start to collapse with lateral deflection in the buckling phase (2), exhibiting similar behaviors (descent hyperbolic-like curves). However, the damaged panel is equivalently deflected (under equal axial displacements) with lower loads and it enters failure phase (3) much sooner (more catastrophic behavior), while the panel without damage is still in its middle buckling range. Therefore, the impact applied was enough to significantly change the panel response to the buckling test with a performance reduction in the compression (1), buckling (2) and failure (3) phases. Fig. 15(b) shows frontal images of the panels with and without impact damage at key moments as indicated in
Fig. 15(a). The panel with damage had its lateral deflection going from its upper surface (side of impact) towards its lower surface during buckling. As seen, the impact-damaged panel exhibits corrugation of the upper metal sheet transversally crossing its central region much earlier. For the panel without damage, this corrugation probably takes place when bending leads to significant difference of deformation between the metal sheet and the composite, which leads to debonding (failure) of these parts. For the panel with damage, the corrugation (failure) is anticipated due to local existing debonding, previously caused by impact, between the metal sheet and the composite. As the panels are bent, the corrugation is laterally spread.

Fig. 16(a) shows the general panorama of the load versus axial displacement evolution in buckling tests of all panel types after impact damaging. Fig. 16(b), 16(c) and (d), respectively, show the compression, buckling and failure phases in detail. The resultant values of maximum compressive load, load at failure and correspondent axial displacements are shown in Fig. 17(a). The axial displacement at failure is shown as alternative to the correlated lateral deflection. As seen, the panel consisted only of composite 

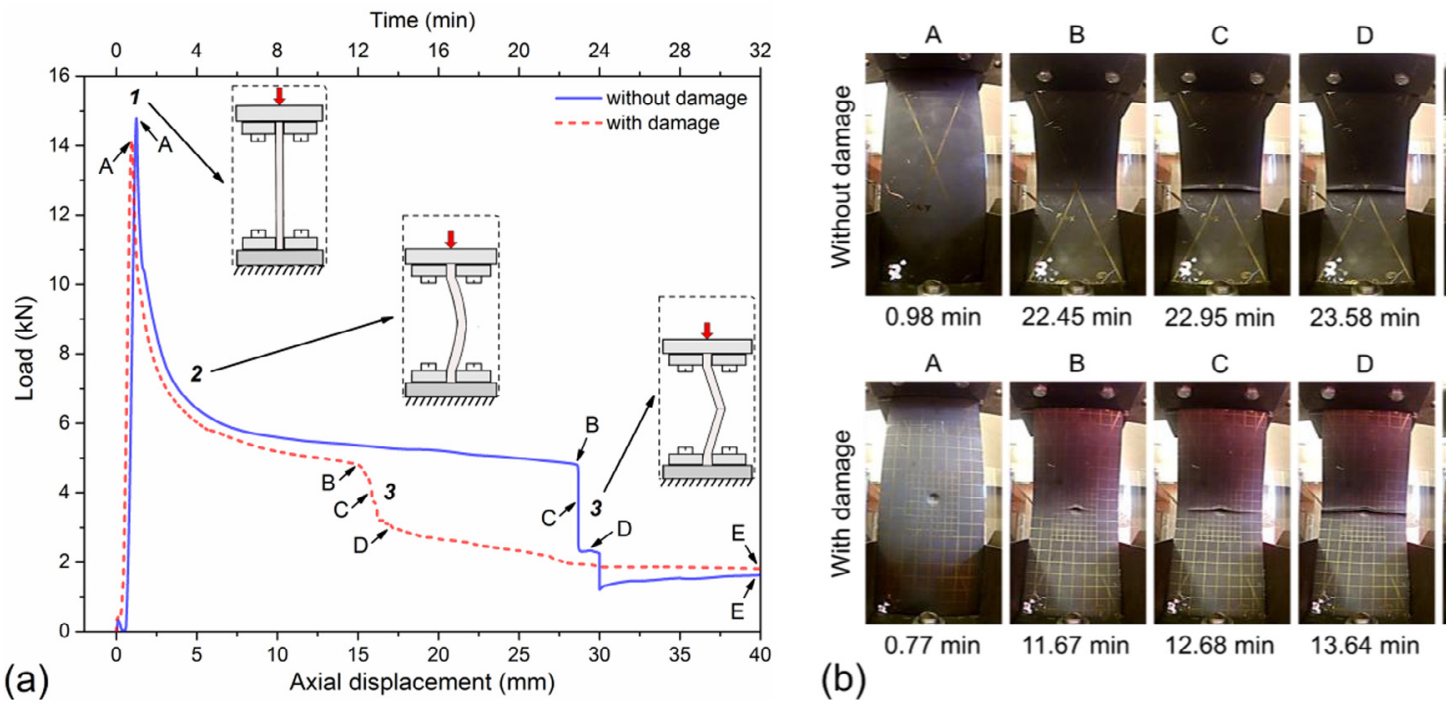

E
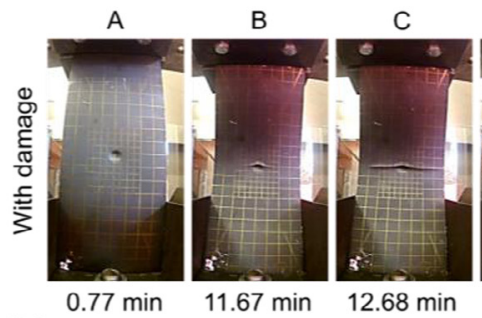

(b)

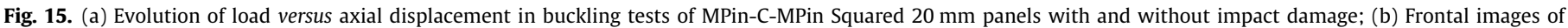
panels with and without impact damage at key moments (indicated in (a)) during buckling test, where: 1 - maximum compressive load; 2 - buckling; 3 - failure.

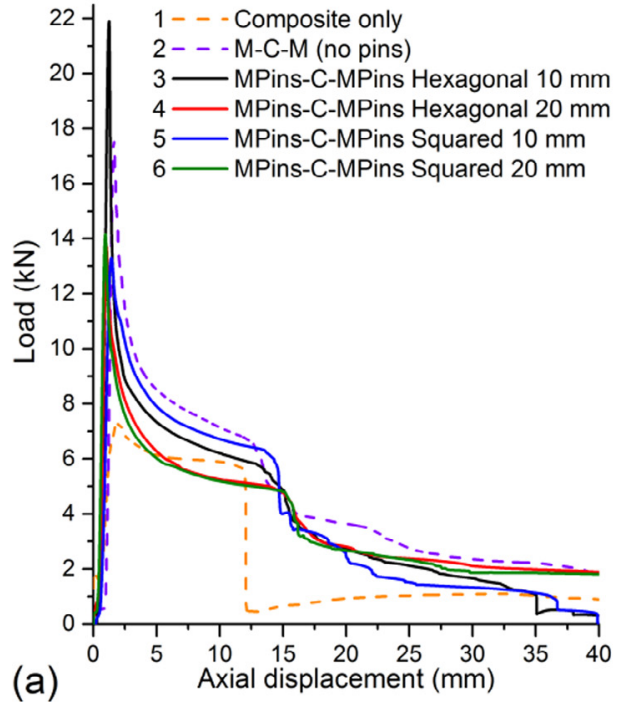

(a)

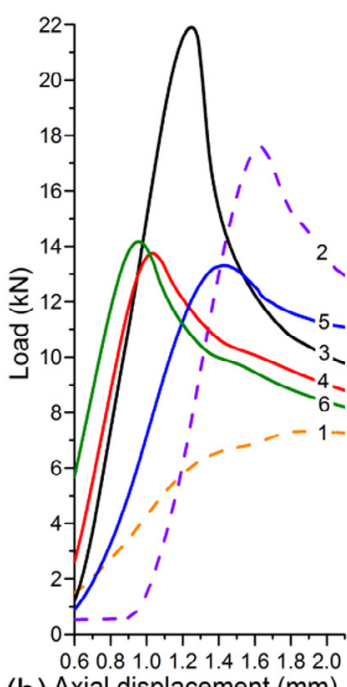

(b) Axial displacement ( $\mathrm{mm})$

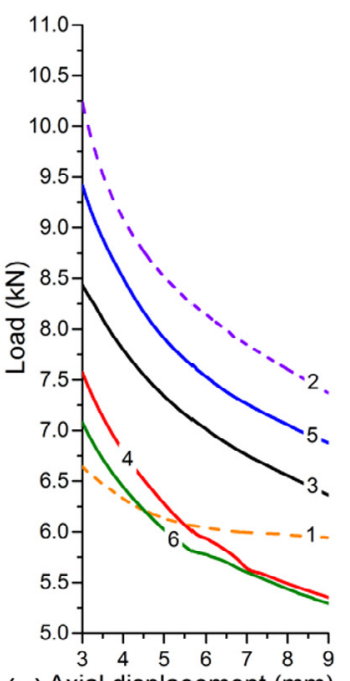

(c) Axial displacement ( $\mathrm{mm})$

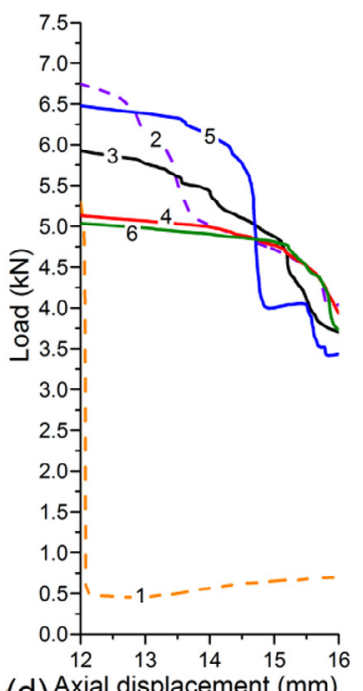

(d) Axial displacement ( $\mathrm{mm})$

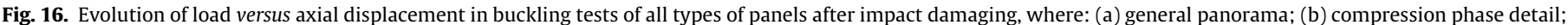
(c) buckling phase detail; (d) failure phase detail.

supported the lowest maximum compressive load, again an indication of its typical low damage tolerance. The conventional FML panel (M-C-M (no pins)), as expected, tolerated more compressive load. The panels with pins had a close performance, with exception of the MPin-C-MPin Hexagonal $10 \mathrm{~mm}$ panel, which was able to bear a notably higher maximum compressive load. All panels with pins achieved maximum compressive loads at around $1.2 \mathrm{~mm}$ of axial displacement and the other panels at around $1.5 \mathrm{~mm}$. As seen in Fig. 16(c), all panels behaved similarly in the buckling phase, with an evolution of load versus axial displacement as described in Fig. 15(a). The conventional FML panel (M-C-M (no pins)) supported the highest loads during deflection, followed closely by the panels with pins deposited in less-spaced patterns (MPin-CMPin Squared $10 \mathrm{~mm}$ and MPin-C-MPin Hexagonal $10 \mathrm{~mm}$ panels in this order). The panels with pins deposited in more-spaced patterns endured lower loads during buckling, but very close to each other especially in longer axial displacements. Similarly, the panel consisting only of composite also supported low loads. The fact that some types of panels with pins had superior performance will be focus of future investigation.

Concerning the phase of failure (Fig. 16(d)), as numerically shown in Fig. 17(a), despite reaching failure at lower loads, the panels with pins endured more axial displacement. Even though favoring larger damage areas, it seems the pins helped holding the material (metal sheets and composite) together for longer. The pins possibly tend to retard the propagation of debonding between metal sheets and composite, for anchoring them to each other, and even tend to retard the spread of delamination in the composite, for acting as clamps that hold most of its layers together between the metal sheets and pins ball-heads. The panel consisting only of composite showed the lowest strength, reaching failure with less displacement. Thus, as verified in the compression tests, the panels with pins tend to behave less catastrophically in buckling after impact. Fig. 17(b) shows images of all type of panels with impact damage after the buckling test. As expected, all types of panels, as also happened in the case displayed in Fig. 15(b), had 


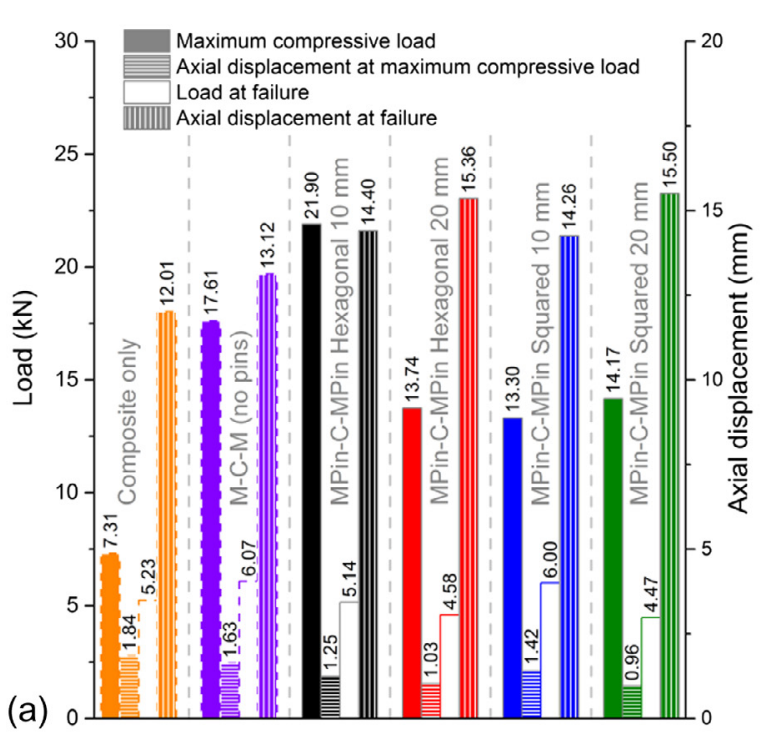

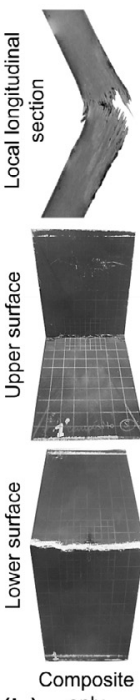

(b) only
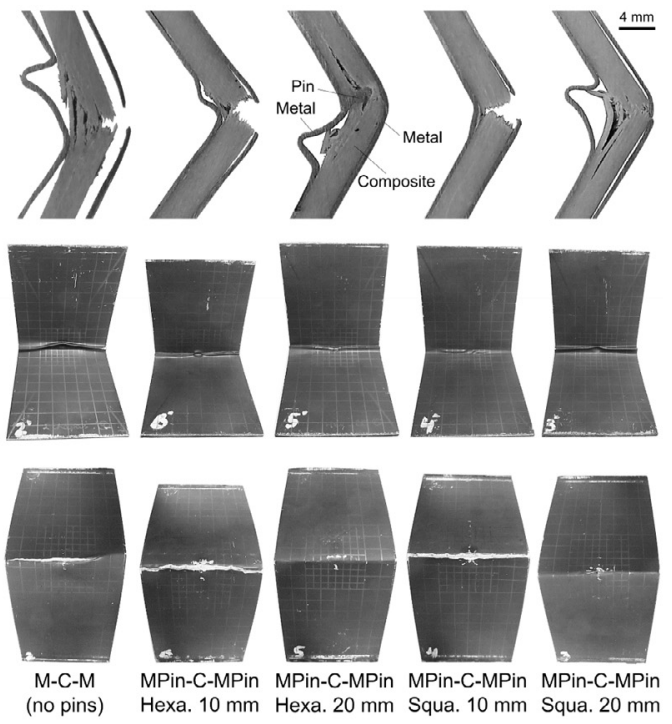

MPin-C-MPin MPin-C-MPin MPin-C-MPin MPin-C-MPin (no pins) Hexa. $10 \mathrm{~mm}$ Hexa. $20 \mathrm{~mm}$ Squa. $10 \mathrm{~mm}$ Squa. $20 \mathrm{~mm}$

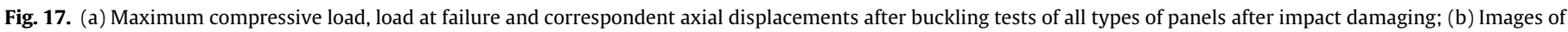
all type of panels with impact damage after buckling test (the pins are not generally seen in the local longitudinal cross sections due to cutting alignment).

their lateral deflection going from the upper surface (side of impact) towards the lower surface. All panels collapsed and ended folded with presence of corrugations transversally crossing the areas of damage. Some of the panels even had the lower metal sheet torn transversally across the damage areas during buckling. This is surely consequence of high tensile stresses localized between the adjacent lines of pins, particularly with the lessspaced deposition patterns, as they act limiting the metal sheets to strain beyond this central area - the pins anchor the metal sheets to the composite and so the strain of the metal sheets is restricted. As also displayed in Fig. 17(b), the conventional FML panel (M-C-M (no pins)) ended with the metal sheets almost totally separated from the composite after impact damaging followed by buckling. In contrast, the FML panels with pins, especially those with less-spaced deposition patterns, exhibited metal sheets-composite debonding notably concentrated around the damage areas. This fact ratifies that the pins effectively anchor the metal sheets to the composite, even after impact damage.

\section{Conclusions}

This work showed that metal pins can be deposited by CMT welding (CMT PIN) on metal surfaces used in FML panels as an economical and practical operation. Considering the conditions applied (miniaturized panels, materials and thicknesses), the following further conclusions are highlighted:

- In terms of impact energy dissipation, all FML panels with pins exhibited similar performance, generally equivalent to the conventional FML panel (M-C-M (no pins)), but significantly higher than that achieved with the panel consisting only of composite. Besides, the addition of weight by the pins as anchorages does not penalize the capacity of the panels to dissipate impact energy, as all panel types dissipated similar levels of specific energy during impact. Therefore, the pins did not make the FML panels more brittle and the change in their deposition pattern did not show any significant effect concerning the capacity of the panels to dissipate impact energy;

- Concerning the damage depth profiles caused by drop-weight testing, all FML panels with pins suffered damages similar to that of the conventional FML panel (M-C-M (no pins)), but not as concentrated as verified in the panel consisting only of composite. Overall, regardless of the deposition pattern, the pins increased the maximum permanent deformation after impact, especially if less spaced. The in-plane damage extents, estimated by infrared thermography, were larger for the FML panels with pins, intermediate for the conventional FML panel (without pins) and much smaller for the composite panel, corroborating the respective damage depth profiles and their connection with the impact energy dissipation;

- Regarding damage tolerance, the FML panels with pins exhibited a less catastrophic trend, i.e., achieving significantly higher loads at longer axial displacements in compression testing, even with previous larger damages. However, in buckling testing after impact, the less catastrophic trend is not so evident, but the pins tend to retard the debonding propagation between metal sheets and composite, for anchoring them to each other. The pins also hold back the delamination spreading in the composite, for clamping the layers together between the metal sheets and ball-heads of the pins.

To sum up, the production of FML panels with pins by CMT welding is a feasible industrial technique. The compression and buckling tests indicated that the pins have potential to improve FML panels damage tolerance. This reinforcement approach would find application in the aerospace, naval, offshore and even military industries for impact-tolerant-lightweight structures and other types of energy-dissipation barriers such as anti-explosive containers and general armor.

\section{Acknowledgments}

The authors acknowledge the Center for Research and Development of Welding Processes (Laprosolda) at UFU and the Department of Materials and Technology at UNESP-Guaratinguetá, for providing laboratorial infrastructure and support, and ALLTEC Materiais Compostos, for providing prepreg materials. They also acknowledge the Brazilian agencies CNPq (Procs. 302863/2016-8 and 303224/2016-9), CAPES (PROEX 0309/2015), and FAPEMIG (Proc. 11304), for research grants and scholarships. 


\section{References}

[1] Vlot A. Impact loading on fibre metal laminates. Int J Impact Eng 1996;18 (3):291-307.

[2] Cortes P, Cantwell WJ. The prediction of tensile failure in titanium-based thermoplastic fibre-metal laminates. Compos Sci Technol 2006;66:2306-16.

[3] Vlot A. Impact properties of fibre metal laminates. Compos Eng 1993;3:911-27.

[4] Sinmazçelik T, Avcu E, Bora MÖ, Çoban O. A review: fibre metal laminates, background, bonding types and applied test methods. Mater Des 2011;32 (7):3671-85. http://dx.doi.org/10.1016/j.matdes.2011.03.011.

[5] Botelho EC, Silva RA, Pardini LC, Rezende MC. A review on the development and properties of continuous fiber/epoxy/aluminum hybrid composites for aircraft structures. Mater Res 2006;9(3):247-56.

[6] Salve A, Kulkarni R, Mache A. A review: fiber metal laminates (FML's) manufacturing, test methods and numerical modeling. Int J Eng Technol Sci (IJETS) 2016;6(1). http://dx.doi.org/10.15282/ijets.6.2016.10.2.1060.

[7] Seydel R, Chang F. Impact identification of stiffed composite panels: i. system development. Smart Mater Struct 2001;10(2):354-69.

[8] Rao HJ, Ramulu PJ, Vardhan MV, Chandramouli CH. Failure prediction in fiber metal laminates for next generation aero materials. IOP Conf Ser: Mater Sci Eng 2016;149(1).

[9] Li X, Yahya MY, Nia AB, Wang Z, Lu G. Dynamic failure of fibre-metal laminates under impact loading - experimental observations. J Reinf Plast Compos 2016;35(4):305-19. http://dx.doi.org/10.1177/0731684415616501.

[10] Jahn J, Weeber M, Boehner J, Steinhilper R. Assessment strategies for composite-metal joining technologies - a review, Procedia CIRP. Procedia CIRP, 2212-8271 2016;50:689-94. http://dx.doi.org/10.1016/i procir.2016.05.034.

[11] Islam MS, Tong L. Influence of pinning on static strength of co-cured metalGFRP hybrid single lap joints. Compos Part A: Appl Sci Manuf, 1359-835X May 2016;84:196-208. http://dx.doi.org/10.1016/i.compositesa.2016.01.011.

[12] Hart-Smith LJ. Bonded-bolted composite joints. J Aircraft 1985;22 (11):993-1000.

[13] Tong L, Mouritz AP, Bannister MK. 3D fiber reinforced polymer composites. Oxford, UK: Elsevier; 2002.

[14] Graham DP, Rezai A, Baker D, Smith PA, Watts JF. The development and scalability of a high strength, damage tolerant, hybrid joining scheme for composite-metal structures. Compos A Appl Sci Manuf 2014;64:11-24. http:// dx.doi.org/10.1016/j.compositesa.2014.04.018.

[15] Earl C, Hilton P, O'Neill B. Parameter influence on surfi-sculpt processing efficiency. Phys Procedia 2012;39:327-35.

[16] Steeves CA, Fleck NA. In-plane properties of composite laminates with through-thickness pin reinforcement. Int J Solids Struct, 0020-7683 May 2006;43(10):3197-212. http://dx.doi.org/10.1016/j.ijsolstr.2005.05.017.

[17] Cartié DDR, Troulis M, Partridge IK. Delamination of Z-pinned carbon fibre reinforced laminates. Compos Sci Technol, 0266-3538 May 2006;66 (6):855-61. http://dx.doi.org/10.1016/i.compscitech.2004.12.018.

[18] Chang P, Mouritz AP, Cox BN. Flexural properties of z-pinned laminates. Compos Part A: Appl Sci Manuf, 1359-835X February 2007;38(2):244-51. http://dx.doi.org/10.1016/i.compositesa.2006.05.004.
[19] Mouritz AP. Review of z-pinned composite laminates. Compos Part A: Appl Sci Manuf, 1359-835X December 2007;38(12):2383-97. http://dx.doi.org/ 10.1016/i.compositesa.2007.08.016.

[20] Stelzer S, Ucsnik S, Pinter G. Fatigue behaviour of composite-composite joints reinforced with cold metal transfer welded pins. Int J Fatigue, 0142-1123 December 2015;81:37-47. http://dx.doi.org/10.1016/j.ijfatigue.2015.06.004.

[21] Fronius, Current welding practice: CMT technology, first edition, Vol 11, DVS Media GmbH, Dusseldorf; 2014.

[22] Ucsnik S, Scheerer M, Zaremba S, Pahr HD. Experimental investigation of a novel hybrid metal-composite joining technology. Compos A Appl Sci Manuf 2010;41(3):369-74. http://dx.doi.org/10.1016/i.compositesa.2009.11.003.

[23] Ucsnik S, Stelzer S, Sehrschön H, Sieglhuberc G, Composite to composite joint with lightweight metal reinforcement for enhanced damage tolerance. In: ECCM16 - 16th European conference on composite materials, 22-26 Jun, 2014, Seville, Spain.

[24] ASTM D7136/D7136M-15. Standard Test method for measuring the damage resistance of a fiber-reinforced polymer matrix composite to a drop-weight impact event.

[25] Ursenbach DO. Penetration of CFP laminates by cylindrical indenters [MSs thesis]. Canada: The University of British Columbia; 1995.

[26] Farooq U, Myler P. Finite element simulation of damage and failure predictions of relatively thick carbon fibre-reinforced laminated composite panels subjected to flat and round noses low velocity drop-weight impact. Thin Walled Struct 2016;104:82-105.

[27] Guillaumat L, Batsale JC, Mourand D. Real time infra-red image processing for the detection of delamination in composite plates. Compos Part A: Appl Sci Manuf, 1359-835X July 2004;35(7-8):939-44. http://dx.doi.org/10.1016/ i.compositesa.2004.01.021.

[28] Meola C, Carlomagno GM. Impact damage in GFRP: new insights with infrared thermography. Compos Part A: Appl Sci Manuf, 1359-835X December 2010;41 (12):1839-47. http://dx.doi.org/10.1016/i.compositesa.2010.09.002.

[29] Lizaranzu M, Lario A, Chiminelli A, Amenabar I. Non-destructive testing of composite materials by means of active thermography-based tools. Infrared Phys Technol, 1350-4495 July 2015;71:113-20. http://dx.doi.org/10.1016/i. infrared.2015.02.006.

[30] Katunin A, Dragan K, Dziendzikowski M. Damage identification in aircraft composite structures: a case study using various non-destructive testing techniques. Compos Struct, 0263-8223 September 2015;127:1-9. http://dx. doi.org/10.1016/i.compstruct.2015.02.080.

[31] Meola C, Boccardi S, Carlomagno GM, Boffa ND, Ricci F, Simeoli G, Russo P. Impact damaging of composites through online monitoring and nondestructive evaluation with infrared thermography. NDT E Int, 0963-8695 January 2017;85:34-42. http://dx.doi.org/10.1016/j.ndteint.2016.10.004.

[32] Ishikawa T, Sugimoto S, Matsushima M, Hayashi Y. Some experimental findings in compression-after-impact (CAI) tests of CF/PEEK (APC-2) and conventional CF/EPOXY flat plates. Compos Sci Tech 1995;55:349-63.

[33] De Freitas M, Reis L. Damage growth analysis of low velocity impacted composite panels. Compos Struct 1997;38(1-4):509-15.

[34] ASTM D7137/D7137M-12. Standard Test Method for Compressive Residual Strength Properties of Damaged Polymer Matrix Composite Plates. 